(C) 2020, The Authors. Published by Elsevier Inc. and Fass Inc. on behalf of the American Dairy Science Association ${ }^{\circledR}$. This is an open access article under the CC BY-NC-ND license (http://creativecommons.org/licenses/by-nc-nd/4.0/).

\title{
Bayesian estimation of genetic variance and response to selection on linear or ratio traits of feed efficiency in dairy cattle
}

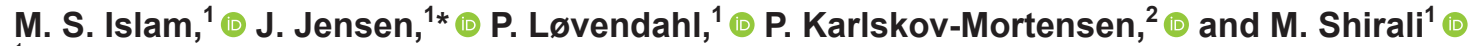 \\ ${ }^{1}$ Center for Quantitative Genetics and Genomics, Aarhus University, 8830 Tjele, Denmark \\ ${ }^{2}$ Division of Animal Genetics, Bioinformatics and Breeding, Department of Veterinary and Animal Sciences, University of Copenhagen, \\ Frederiksberg 1870, Denmark
}

\begin{abstract}
This study aimed to estimate genetic parameters of the linear trait genetic residual feed intake (RFI) and the ratio traits feed conversion ratio (FCR) and feed conversion efficiency (FCE) along with dry matter intake (DMI) and energy sink traits such as energy-corrected milk (ECM), body weight (BW), body condition score (BCS), and BW change (BWC) across different weeks in the first lactation of Danish Holstein cows. A second objective was to conduct a Bayesian analysis of direct and correlated superiority of the selected group when selecting on genetic RFI, FCR, or FCE. Feed intake and energy sink traits were recorded during wk 1 to 44 of lactation on 847 primiparous Danish Holstein cows. A Bayesian multivariate random regression animal model was used to analyze DMI, ECM, BW, and BCS in different weeks of lactation. Genetic RFI was obtained by conditioning DMI on ECM, BW, BCS, and BWC using genetic partial regression coefficients. The posterior distribution of the breeding values for FCR and FCE was derived from the posterior distribution of functions of "fixed" environmental effects and random additive genetic effects on DMI and ECM. Genetic superiority of the selected group was defined as the difference in additive genetic mean of the selected top individuals expected to be potential parents, and the total population after integrating genetic trends out of the posterior distribution of selection responses. Posterior means of heritability of genetic RFI ranged from 0.10 to 0.15 , genetic variance of FCR and FCE ranged from $2.13 \times$ $10^{-3}$ to $3.2 \times 10^{-3}\left(\mathrm{~kg}^{2} \mathrm{DMI} / \mathrm{kg}^{2} \mathrm{ECM}\right)$ and $6.11 \times 10^{-3}$ to $2.4 \times 10^{-2}\left(\mathrm{~kg}^{2} \mathrm{ECM} / \mathrm{kg}^{2} \mathrm{DMI}\right)$, respectively. Selection against RFI showed a direct response of -1.01 to $-2.23 \mathrm{~kg} / \mathrm{d}$ RFI and correlated responses of -0.031 to $-0.056 \mathrm{~kg} / \mathrm{kg}$ for FCR, 0.104 to $0.160 \mathrm{~kg} / \mathrm{kg}$ for FCE, and -0.316 to $-1.057 \mathrm{~kg} / \mathrm{d}$ for DMI in different weeks of lactation. Selection against RFI had no
\end{abstract}

Received June 21, 2019.

Accepted May 5, 2020.

*Corresponding author: just.jensen@mbg.au.dk significant effect on production traits but selection for ratio traits reduced $\mathrm{BW}$ and $\mathrm{BCS}$. Posterior means of genetic correlation between DMI and ratio traits were low. In conclusion, the Bayesian procedure allowed us to estimate genetic RFI without the need for separate multiple regression analysis and considered the nonnormal posterior distribution of ratio traits. Selection against genetic RFI might be an effective means to improve feed efficiency compared with ratio traits for feed efficiency in dairy cattle.

Key words: dairy cattle, feed efficiency, genetic variance, lactation period, response to selection

\section{INTRODUCTION}

Improvements in feed efficiency could reduce land use as well as other resources used for feed production and may help to reduce unwanted greenhouse gas emissions (Løvendahl et al., 2018). Additionally, reductions in feed usage could result in economic benefits for dairy producers (Hardie et al., 2017); therefore, feed efficiency is an important part of the potential breeding objective for dairy cattle. Although direct selection for feed efficiency is a commonly used breeding objective in pigs and poultry (Emmerson, 1997; Shirali et al., 2018), it is still not widely used in dairy cattle breeding programs (Hurley et al., 2017). In addition, there is no consensus on a definition of feed efficiency for lactating animals, and the main barrier for not including feed efficiency in dairy cattle breeding programs is the unavailability of sufficient records of individual feed intake for the estimation of net feed efficiency on commercial farms. Recording individual feed intake is currently restricted to research farms and nucleus breeding herds, where the amount of available data is limited. However, feed intake is reported to be genetically heritable (Berry et al., 2014) although high accuracy in prediction of breeding values for feed intake of individual animal remains difficult to achieve because of limited data size.

Feed efficiency can be defined as a linear or as a ratio trait (Shirali et al., 2018). One of these traits is residual feed intake (RFI), which is a linear trait originally pro- 
posed by Koch et al. (1963). Classically, RFI refers to actual feed intake minus expected feed intake based on production traits. Ratio traits such as feed conversion ratio (FCR) in dairy cattle is defined as input (net energy feed intake) over output (ECM). In addition to FCR, the most commonly used ratio trait measure of feed efficiency in dairy cattle is feed conversion efficiency (FCE), which is the inverse of FCR. Coleman et al. (2010) defined FCE as milk production per kilogram of BW in dairy cattle. This ratio trait has some limitations in dairy cattle breeding because dairy cows experience body tissue mobilization and catabolism along the lactation curve, which is not accounted for in this definition (Berry and Crowley, 2013). Another limitation is that ratio traits depend on the joint distribution of 2 component traits. Moreover, direct selection on ratio traits might result in unexpected genetic gain in the component traits (Gunsett, 1984). To address the limitations of ratio traits such as their non-normal distribution, Shirali et al. (2018) derived an alternative Bayesian expression for FCR, accounting for inaccuracy in parameter estimation and for the non-normal distribution of ratio traits while estimating direct and correlated responses to selection.

Koch et al. (1963) computed 4 partial regressions to adjust feed consumption for differences in gain followed by another step for genetic analysis to derive a linear trait of feed efficiency in beef cattle. Alternatively, breeding values and the posterior distributions of RFI could be derived following the Bayesian framework by conditioning breeding values of feed intake on energy sink traits. In this way, it is unnecessary to obtain regression coefficients from separate multiple regression analysis to derive RFI. Additionally, phenotypic and genetic RFI can be derived using partial phenotypic and genetic regression coefficients, respectively (Shirali et al., 2018).

The aims of this study were (1) to estimate genetic parameters of linear trait of genetic RFI and ratio traits of FCR and FCE, along with DMI and energy sink traits such as ECM, BW, BCS, and BW change (BWC) across different weeks in the first lactation of Danish Holstein cows; and (2) to estimate the genetic superiority of the selected group when performing single-trait selection on genetic RFI, FCR, or DMI.

\section{MATERIALS AND METHODS}

\section{Data Recording}

Data on Danish Holstein cows were obtained from the herd located at the Danish Cattle Research Center (Foulum, Denmark). Raw data included information on 896 Holstein cows in their first, second, and third parities that were born between 1997 and 2016. Only data from 847 cows in the first parity were used for the present study. A detailed description of the data set and animal management is available in $\mathrm{Li}$ et al. (2016, 2017) and Løvendahl and Chagunda (2011). Briefly, from 1 to 44 wk of lactation, all cows were fed a TMR, and individual feed intakes were recorded electronically (RIC system, Insentec, Marknesse, the Netherlands). A maximum of $3 \mathrm{~kg}$ of concentrate per cow per day was given to each cow at milking in the automatic milking system. The actual amount of concentrates given during milking depended on the hours since last milking, and the supply of concentrates was controlled by the VMS management software (DeLaval International, Tumba, Sweden). Leftovers of concentrates during each milking were recorded by the automatic milking system. The DMI per cow was expressed as the average of weekly sums of feed intake records for each week in lactation. Individual milk yield was recorded by the automatic milking system at each milking but milk yield was expressed as the average of daily yield over $7 \mathrm{~d}$. Milk composition was obtained by analyzing 4 to 8 milk samples collected over a continuous 48 -h period each week. Milk components were also expressed as weekly measurements. Body weight was recorded automatically at each milking and expressed as a weekly average, and BCS was assessed every 2 wk by trained observers on a scale of 1 to 5 .

\section{Data Editing}

Energy-corrected milk per cow for each lactation week was calculated from milk yield and milk composition using the formula by Sjaunja et al. (1990):

$$
\begin{gathered}
\text { ECM }(\mathrm{kg})=\text { milk yield }(\mathrm{kg}) \\
\times\{[38.30 \times \text { fat content }(\mathrm{g} / \mathrm{kg})+24.20 \\
\times \text { protein content }(\mathrm{g} / \mathrm{kg})+16.54 \\
\times \text { lactose content }(\mathrm{g} / \mathrm{kg})+20.7] / 3,140\}
\end{gathered}
$$

The studied traits were DMI, EMC, BW, and BCS. The age at first calving ranged from 653 to $1,099 \mathrm{~d}$ (Table 1). Pedigree information was extracted from the Nordic cattle genetic evaluation (NAV, Skejby, Denmark) and traced back for at least 4 generations; the total pedigree included 3,456 animals.

\section{Statistical Analysis}

Multivariate random regression analysis was performed for DMI, ECM, BW, and BCS in the first lactation using the following multivariate model: 


$$
\mathbf{y}=\mathbf{X b}+\mathbf{Z a}+\mathbf{W p e}+\mathbf{e}
$$

where $\mathbf{y}$ is the vector of phenotypic records containing sub-vectors for DMI, ECM, and BW in each week of first lactation and BCS at 2- to 3-wk intervals of first lactation; $\mathbf{b}$ is the fixed effects of week of lactation (1 to $44 \mathrm{wk}$ of lactation) with a sub-vector for each trait. Fixed for all traits were year by season of recording (4 seasons were defined: March to May, June to August, September to November, December to February) and the coefficient of a linear regression on calving age; $\mathbf{a}$ is the vector of random regressions for random additive genetic effect, and pe is the vector of random regressions for random permanent environmental effect of the cows. Both a and pe contained sub-vectors for each of the traits DMI, ECM, BW, and BCS. Weekly means of DMI, ECM, and BCS per cow across the 44 wk of lactation were modeled by first-order Legendre polynomials; weekly means of BW were modeled by second-order Legendre polynomials for random additive genetic effect, and first-order Legendre polynomials were used to model random permanent environmental effect. Order of fit was same for both a and pe for the traits of DMI, $\mathrm{ECM}$, and BCS. $\mathbf{e}$ is the vector of random residual effects containing sub-vectors for DMI, ECM, BW, and $\mathrm{BCS}$, respectively. $\mathbf{X}$ is the corresponding design matrix for fixed effects, and $\mathbf{Z}$ and $\mathbf{W}$ are the corresponding covariable matrices containing Legendre polynomial coefficients corresponding to week of lactation. All design matrices $(\mathbf{X}, \mathbf{Z}$, and $\mathbf{W})$ can be subdivided corresponding to each trait in the model.

In the present study, a full Bayesian analysis was accomplished and, therefore, priors were specified for all parameters. Prior distributions for all random vectors were multivariate normal distributions with a mean of zero, and

$$
\operatorname{Var}\left(\begin{array}{c}
\mathbf{e}_{D M I} \\
\mathbf{e}_{E C M} \\
\mathbf{e}_{B W} \\
\mathbf{e}_{B C S}
\end{array}\right)=\mathbf{R}_{0, i} ; \mathbf{R}_{0, i}=\operatorname{diag}\left(\mathbf{R}_{0,1}, \mathbf{R}_{0,2}, \ldots, \mathbf{R}_{0,44}\right)
$$

Table 1. Descriptive statistics of DMI (kg/d), ECM (kg/d), BW (kg), and BCS across 44 lactation weeks of primiparous Holstein cows

\begin{tabular}{lrrrc}
\hline Trait & Mean & SD & $\begin{array}{c}\text { No. of } \\
\text { records }\end{array}$ & $\begin{array}{c}\text { No. of } \\
\text { animals }\end{array}$ \\
\hline DMI & 19.39 & 3.13 & 28,718 & 846 \\
ECM & 30.17 & 5.90 & 26,305 & 830 \\
BW & 611.72 & 65.85 & 28,147 & 845 \\
BCS & 3.19 & 0.28 & 12,590 & 828 \\
\hline
\end{tabular}

where the second subscript of $\mathbf{R}_{0, i}$ corresponds to week of lactation ( $i=1$ to 44 ) so that the residual covariance matrix was different in each week of lactation.

$$
\operatorname{Var}\left(\begin{array}{c}
\mathbf{a}_{D M I} \\
\mathbf{a}_{E C M} \\
\mathbf{a}_{B W} \\
\mathbf{a}_{B C S}
\end{array}\right)=\mathbf{A} \otimes \mathbf{G}_{0},
$$

where $\mathbf{A}$ is the additive genetic relationship matrix, $\mathbf{G}_{0}$ is a $9 \times 9$ matrix of additive genetic (co)variances for DMI, ECM, BW, and BCS, and $\otimes$ is the Kronecker product. The genetic covariance matrices have order 9 because of random intercepts and linear regressions on week of lactation for DMI, DCM, and BCS, and intercept, linear, and quadratic regressions for $\mathrm{BW}$.

For the permanent environmental (co)variance matrix, all sub-models contained random intercept and linear regression on week of lactation:

$$
\operatorname{Var}\left(\begin{array}{c}
\mathbf{p} \mathbf{e}_{D M I} \\
\mathbf{p e}_{E C M} \\
\mathbf{p e}_{B W} \\
\mathbf{p e}_{B C S}
\end{array}\right)=\mathbf{I} \otimes \mathbf{P} \mathbf{e}_{0}
$$

where $\mathbf{P e}_{0}$ is an $8 \times 8$ matrix of permanent environmental (co)variances. The random effects of a, pe, and $\mathbf{e}$ were considered independent of each other. Flat priors were assumed for fixed effects in $\mathbf{b}$ and for all dispersion parameters $\mathbf{R}_{0, i}, \mathbf{G}_{0}$, and $\mathbf{P e}_{0}$. See Eq. [2] in the following, where the diagonals of the matrices are the variances $(i, l$, and $q$ are the intercept, linear, and quadratic effects in the Legendre polynomials, respectively) and the off-diagonals are the covariances.

Bayesian analysis via Gibbs sampling was used to obtain posterior distributions for all parameters that were included in the multivariate model [1], including the matrices of variances and covariances. The Gibbs sampler was run for 1.1 million rounds, with the first 100,000 rounds considered as burn-in; after the burnin, every 500th sample of all location and dispersion parameters was saved for posterior analysis. The RJMC module in the DMU software package by Madsen and Jensen (2013) was used for the analysis.

\section{Analysis of Posterior Distributions}

A total of 2,000 samples from the joint posterior distribution of all location and (co)variance parameters from the multivariate model [1] were saved for post- 


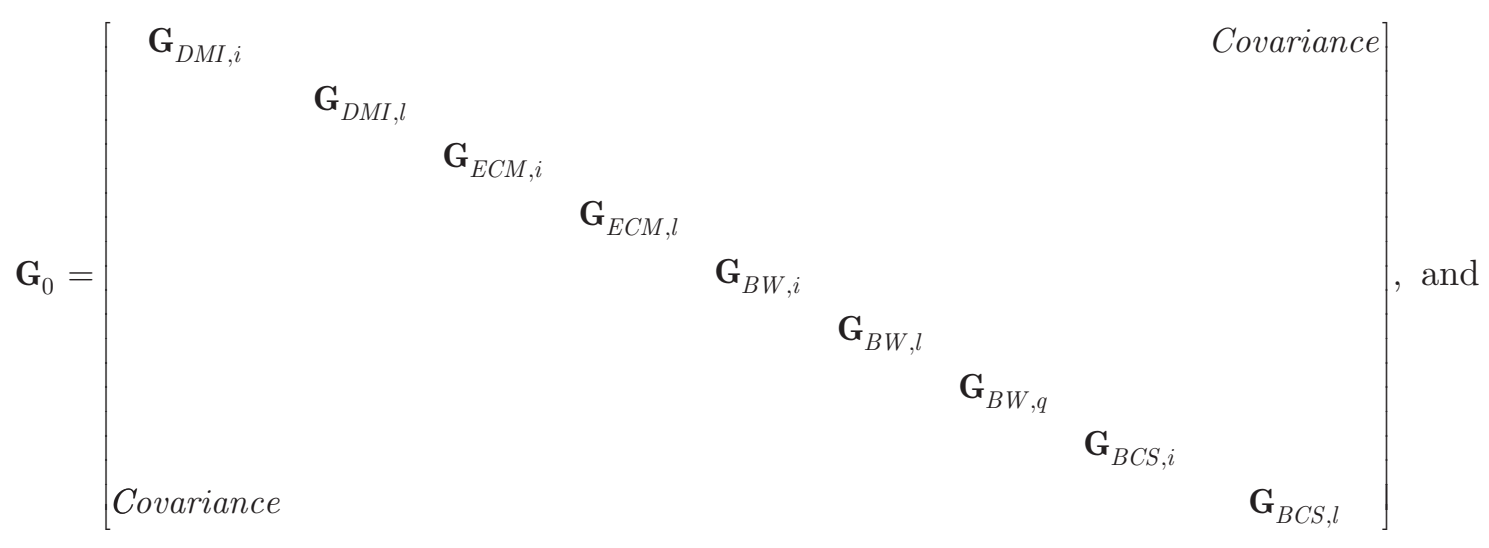

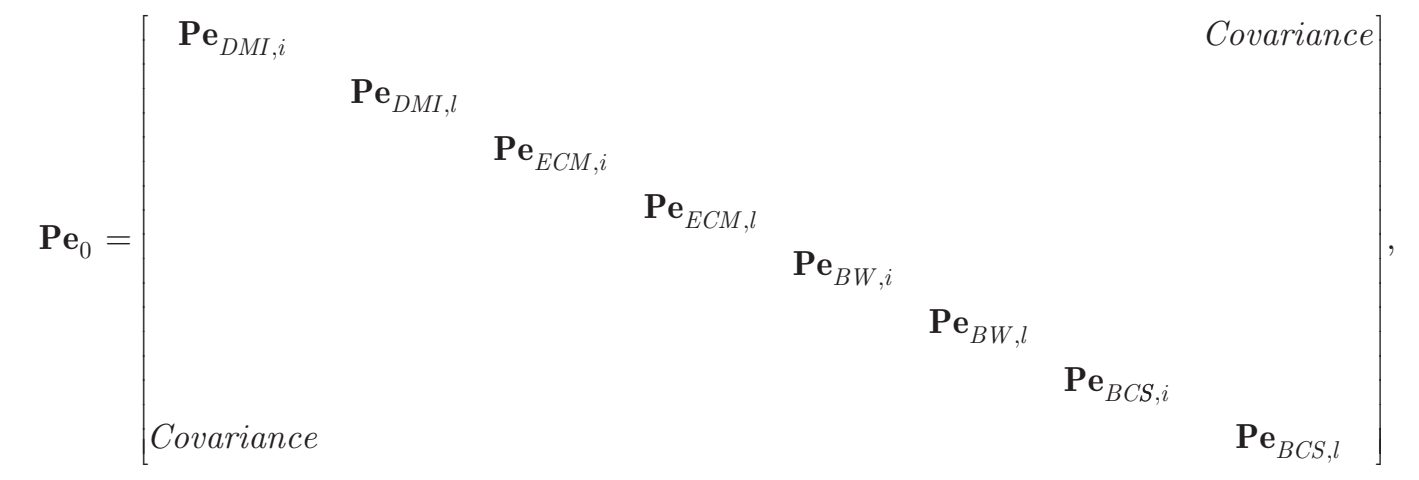

$$
\begin{aligned}
& \mathbf{\Phi}_{1}=\left[\begin{array}{ccccccccc}
L P_{i} & L P_{l}(1) & 0 & 0 & 0 & 0 & 0 & 0 & 0 \\
0 & 0 & L P_{i} & L P_{l}(1) & 0 & 0 & 0 & 0 & 0 \\
0 & 0 & 0 & 0 & L P_{i} & L P_{l}(1) & L P_{q}(1) & 0 & 0 \\
0 & 0 & 0 & 0 & 0 & 0 & 0 & L P_{i} & L P_{l}(1) \\
0 & 0 & 0 & 0 & L P_{i}-L P_{i} & L P_{l}(2)-L P_{l}(1) & L P_{q}(2)-L P_{q}(1) & 0 & 0
\end{array}\right]
\end{aligned}
$$

Gibbs analysis. The BOA package (Smith, 2007) in $\mathrm{R}$ (https://www.R-project.org/) was used for convergence diagnostics through statistical and graphical analysis of the posterior distributions of the (co)variances, location, and derived parameters investigated. We also looked at the effective sample size, which was $>100$ for all parameters in our study.

\section{Derivation of (Co)variances for BWC for Each Week of Lactation}

The (co)variance components of BWC in each lactation week were obtained from the slope of the fitted BW curve of each cow using first differences. First, a matrix containing Legendre polynomial coefficients from 1 to $44 \mathrm{wk}$ of lactation for DMI, ECM, BW, and BCS was defined. Legendre polynomial coefficients for BWC were estimated using the first differences in 2 consecutive weeks from Legendre polynomial coefficients for BW. The matrix $\left(\boldsymbol{\Phi}_{1}\right)$ containing coefficients of Legendre polynomial for the first week of lactation for DMI, ECM, BW, BCS, and BWC was made as in Eq. [3], where $L P_{i}$ is the intercept of Legendre polynomial, $L P_{l}(1)$ is the linear effect for the coefficient of Legendre polynomial in the first week, $L P_{l}(2)$ is the linear effect for the coefficient of Legendre polynomial in the second week, $L P_{q}(1)$ is the quadratic effect for the coefficient of Legendre polynomial in first week, and $L P_{q}(2)$ is the quadratic effect for the coefficient of Legendre polynomial the second week. The first 4 rows in matrix $\left(\boldsymbol{\Phi}_{1}\right)$ are for the traits of DMI, ECM, BW, and BCS, respectively. The fifth row of $\boldsymbol{\Phi}_{1}$ is to derive the coefficient of Legendre polynomial for BWC. The coefficient of Legendre polynomial for BWC at wk 44 of lactation was same as that of wk 43 of lactation. Thus, the dimension of matrix $\boldsymbol{\Phi}$ was $220 \times 9$. 
The $\mathbf{G}$ matrix was obtained as follows: $\mathbf{G}=\mathbf{\Phi} \mathbf{G}_{0} \boldsymbol{\Phi}^{\prime}$. The final $\mathbf{G}$ matrix contained the genetic (co)variances of DMI, ECM, BW, BCS, and BWC, and the $\mathbf{G}$ matrix was $5 \times 5$ in each of $44 \mathrm{wk}$ of lactation; that is, in total, a matrix of dimension $220 \times 220$.

Likewise, the Pe matrix contained permanent environmental (co)variances and was obtained as follows: $\mathbf{P e}=\boldsymbol{\Phi} \mathbf{P e}_{0} \boldsymbol{\Phi}^{\prime}$, where the dimension of $\boldsymbol{\Phi}$ was $220 \times 8$, because the permanent environmental variance of $\mathrm{BW}$ was modeled by first-order Legendre polynomial. The dimension of the $\mathbf{P e}$ matrix was also $220 \times 220$. $\mathbf{R}$ was a block diagonal matrix, where each block contained residual (co)variances for DMI, ECM, BW, BCS, and BWC at each lactation week, resulting in a matrix of $220 \times 220$.

The transformation matrix to convert the $\mathbf{R}_{0, i}$ matrix into the final $\mathbf{R}$ matrix was made as follows:

$$
\mathbf{t}_{1}=\left[\begin{array}{cccccccc}
1 & 0 & 0 & 0 & 0 & 0 & 0 & 0 \\
0 & 1 & 0 & 0 & 0 & 0 & 0 & 0 \\
0 & 0 & 1 & 0 & 0 & 0 & 0 & 0 \\
0 & 0 & 0 & 1 & 0 & 0 & 0 & 0 \\
0 & 0 & -1 & 0 & 0 & 0 & 1 & 0
\end{array}\right],
$$

where $\mathbf{t}_{1}$ is the transformation matrix for the first week of lactation to derive residual variance for $\mathrm{BWC}$, the first 4 rows of $\mathbf{t}_{1}$ indicate residual variances for DMI, ECM, BW, and BCS, respectively, and the fifth row was added to derive the residual variance for BWC. $\mathbf{R}_{0,12}$ was the block diagonal matrix for the first and second weeks of lactation, having the dimension of 8 $\times 8$.

The residual matrix for the first week of lactation, $\mathbf{R}(1)$, was obtained as follows:

$$
\mathbf{R}(1)=\mathbf{t}_{1} \mathbf{R}_{0,12} \mathbf{t}_{1}{ }^{\prime}
$$

where the dimension of $\mathbf{R}(1)$ matrix is $5 \times 5$. Thus, we obtained a final $\mathbf{R}$ matrix having a dimension of $220 \times$ 220. The phenotypic (co)variance matrix was defined as $\mathbf{P}=\mathbf{G}+\mathbf{P e}+\mathbf{R}$.

\section{Posterior Distribution of Genetic RFI}

Statistical analysis for genetic parameter estimation and prediction of breeding values for RFI, FCR, and FCE as measurements of feed efficiency were done as in Shirali et al. (2018). Residual feed intake was defined as genetic RFI, obtained by correcting breeding values of DMI on breeding values of ECM, BW, BCS, and BWC using partial genetic regression coefficients, making sure that genetic (co)variances between RFI and production traits (ECM, BW, BCS, and $\mathrm{BWC}$ ) were zero. Body weight was used in Eq. [5] as an indicator of maintenance requirement of the cows. Here, the derivation of variance parameters and breeding values for RFI was shown, and RFI was derived as linear combinations of the energy sink traits in the analysis. These derivations were used on all samples obtained from the Gibbs sampler to obtain the posterior distributions of (co)variances and breeding values for RFI definition. For RFI, the partial genetic regression coefficients $\left(\mathbf{b}_{\mathrm{G}}\right)$ for ECM, BW, BCS, and BWC on a weekly basis were computed from the corresponding diagonal sub-genetic (co)variance matrices $(\mathbf{G})$. The partial phenotypic regression coefficients $\left(\mathbf{b}_{\mathrm{P}}\right)$ were also computed weekly from the corresponding diagonal sub-phenotypic (co) variance matrices $(\mathbf{P})$.

Bayesian estimations of partial phenotypic $\left(\mathbf{b}_{\mathrm{P}}\right)$ and genetic $\left(\mathbf{b}_{\mathrm{G}}\right)$ regression coefficients in each lactation week were obtained as follows:

$$
\mathbf{b}_{\mathrm{P}}=\mathbf{P}_{\mathrm{P}}^{-1} \mathbf{P}_{p, D M I} \text { and } \mathbf{b}_{\mathrm{G}}=\mathbf{G}_{\mathrm{P}}^{-1} \mathbf{G}_{p, D M I}
$$

which are $4 \times 1$ vector-valued functions in each lactation week that are obtained in each sample of the Gibbs output. $\mathbf{G}_{\mathrm{P}}$ is $4 \times 4$ matrix of genetic (co)variance for the production traits of ECM, BW, BCS, and BWC at each lactation week from $\mathbf{G}$. Matrix $\mathbf{G}_{p, D M I}$ represents the genetic covariances of the production traits ECM, BW, BCS, and BWC with DMI at each lactation week.

For partial phenotypic regression coefficients $\left(\mathbf{b}_{\mathrm{P}}\right)$, $\mathbf{P}_{\mathrm{P}}$ is $4 \times 4$ matrix of phenotypic (co)variance at each lactation week for the production traits ECM, BW, BCS, and BWC from $\mathbf{P}$. Matrix $\mathbf{P}_{p, D M I}$ is the phenotypic covariances of the production traits ECM, BW, BCS, and BWC with DMI in each lactation week.

Prediction of breeding values for RFI can be obtained simultaneously for all animals by the distributions of breeding values for DMI $\left(\mathbf{a}_{\mathrm{DMI}}\right)$, conditional on breeding values for ECM $\left(\mathbf{a}_{\mathrm{ECM}}\right), \mathrm{BW}\left(\mathbf{a}_{\mathrm{BW}}\right)$, BCS $\left(\mathbf{a}_{\mathrm{BCS}}\right)$, and BWC $\left(\mathbf{a}_{\mathrm{BWC}}\right)$ using the genetic $\left(\mathbf{b}_{\mathrm{G}}\right)$ partial regression coefficients. A sample from the posterior distribution of breeding values for genetic RFI is as follows:

$$
\mathbf{a R F I}=\mathbf{a}_{\mathrm{DMI}}-\left[\mathbf{a}_{\mathrm{ECM}} \mathbf{a}_{\mathrm{BW}} \mathbf{a}_{\mathrm{BCS}} \mathbf{a}_{\mathrm{BWC}}\right] \mathbf{b}_{\mathrm{G}} .
$$

The corresponding variances and covariances can be obtained in each lactation week using the following equations:

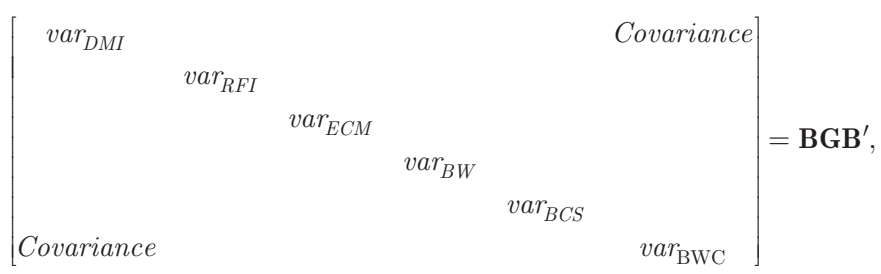


where $\mathbf{B G B}^{\prime}$ represents the genetic (co)variances; and

$$
\mathbf{B}=\left[\begin{array}{ccccc}
1 & 0 & 0 & 0 & 0 \\
1 & -b_{G, E C M} & -b_{G, B W} & -b_{G, B C S} & -b_{G, B W C} \\
0 & 1 & 0 & 0 & 0 \\
0 & 0 & 1 & 0 & 0 \\
0 & 0 & 0 & 1 & 0 \\
0 & 0 & 0 & 0 & 1
\end{array}\right],
$$

where $b_{G, E C M}, b_{G, B W}, b_{G, B C S}$, and $b_{G, B W C}$ are genetic regression coefficients from $\mathbf{b}_{\mathrm{G}}$ for $\mathrm{ECM}, \mathrm{BW}, \mathrm{BCS}$, and $\mathrm{BWC}$, respectively, in each lactation week.

\section{Posterior Distribution of FCR and FCE}

Feed conversion ratio is defined as the ratio of input (DMI) over output (ECM), and FCE is defined as the inverse of FCR. Therefore, the distribution of FCR and FCE depends on means of the 2 normally distributed DMI and ECM and their (co)variance. As a result, the breeding value for FCR depends on "fixed" location parameters, because it depends on the mean of DMI $\left(\mu_{\mathrm{DMI}}\right)$ and ECM $\left(\mu_{\mathrm{ECM}}\right)$. Breeding values for FCR $\left(\mathbf{a}_{\mathrm{FCR}}\right)$ and FCE $\left(\mathbf{a}_{\mathrm{FCE}}\right)$ can be calculated from underlying parameters using the following equations (Shirali et al., 2018):

$$
\begin{gathered}
\mathbf{a}_{\mathrm{FCR}}=\frac{\mu_{\mathrm{DMI}}+\mathbf{a}_{\mathrm{DMI}}}{\mu_{\mathrm{ECM}}+\mathbf{a}_{\mathrm{ECM}}}-\frac{\mu_{\mathrm{DMI}}}{\mu_{\mathrm{ECM}}}, \\
\mathbf{a}_{\mathrm{FCE}}=\frac{\mu_{\mathrm{ECM}}+\mathbf{a}_{\mathrm{ECM}}}{\mu_{\mathrm{DMI}}+\mathbf{a}_{\mathrm{DMI}}}-\frac{\mu_{\mathrm{ECM}}}{\mu_{\mathrm{DMI}}},
\end{gathered}
$$

where the estimate of $\mu_{\mathrm{DMI}}$ and $\mu_{\mathrm{ECM}}$ can be computed from Eq. [1] for DMI and ECM, respectively, as the sum of the fixed effect and in addition to fixed regressions for covariable calving age, which were set to the population average.

\section{Superiority of the Selected Group}

Genetic trends are defined as change in mean breeding values over years. The difference between the mean of the breeding values of selected animals and the mean of the breeding values of all animals corrected for the genetic trend is the Bayesian estimate of the superiority of the selected group. Genetic trends were estimated according to Shirali et al. (2018) as the yearly means of breeding values.

The mean of the selected group for trait $j$ when selecting on trait $j^{\prime}$ can be computed as

$$
a_{j j^{\prime}}^{-s}=\frac{1}{n_{s}} \sum_{i=1}^{n} a_{i j}^{*} \mathbf{I}\left(a_{i j^{\prime}}^{*}>a_{n_{s} j^{\prime}}^{*}\right),
$$

where $a_{i j}^{*}$ is the breeding value for trait $j$ of animal $i$, corrected for the genetic trend; $n$ is the total number of animals; and $a_{n_{s} j^{\prime}}^{*}$ is the trend-corrected breeding value for the individual ranked $n_{s}$ when ordering animals based on trend-corrected breeding values for trait $j^{\prime}$; that is, the cut-off point for selection. If $j=j^{\prime}$, it indicates a direct response to selection for the trait $j$, and if $j \neq j^{\prime}$, it indicates a correlated response to selection in trait $j$ while selecting for trait $j^{\prime}$. In this study, direct and correlated responses to selection for feed efficiency traits in dairy cattle such as genetic RFI, FCR, and DMI are presented. The number of individuals ranked for analysis was decided based on truncation selection of the top 5 to $30 \%$ of animals. We present the results of truncation selection of the top $10 \%$ because results were consistent across all truncation points. Feed efficiency traits were selected downward.

\section{RESULTS}

\section{Genetic Parameters of Feed Efficiency Traits}

Posterior means and standard deviations of heritability and genetic variances of genetic RFI and its component traits are shown in Figures 1, 2, 3, 4, and 5. Almost stable posterior means of genetic variances for RFI across the 44 wk of lactation were observed but we found upward trends of posterior means of DMI and ECM from 20 wk of lactation onward. We observed that posterior means of genetic variances for BW decreased slightly in the first 8 wk of lactation and then remained almost stable in mid lactation. We found very low genetic variances for BWC in mid lactation compared with early and late lactation. Posterior means of heritability for RFI followed the same trend as observed in posterior means of genetic variances. We found substantial heritability (posterior means) ranging from 10 to $15 \%$ for genetic RFI across the 44 wk of lactation. Posterior means of heritability for production traits were $60 \%$ for BW, $30 \%$ for BCS, and $40 \%$ for ECM across different weeks of lactation.

Posterior means of genetic and phenotypic correlations between genetic RFI and DMI across different weeks of lactation are shown in Figure 6. We found that RFI was genetically uncorrelated with its component traits as RFI was estimated using partial genetic regression coefficients, but weak phenotypic correlations were found between RFI and production traits (results not shown). A moderate to low positive genetic correla- 


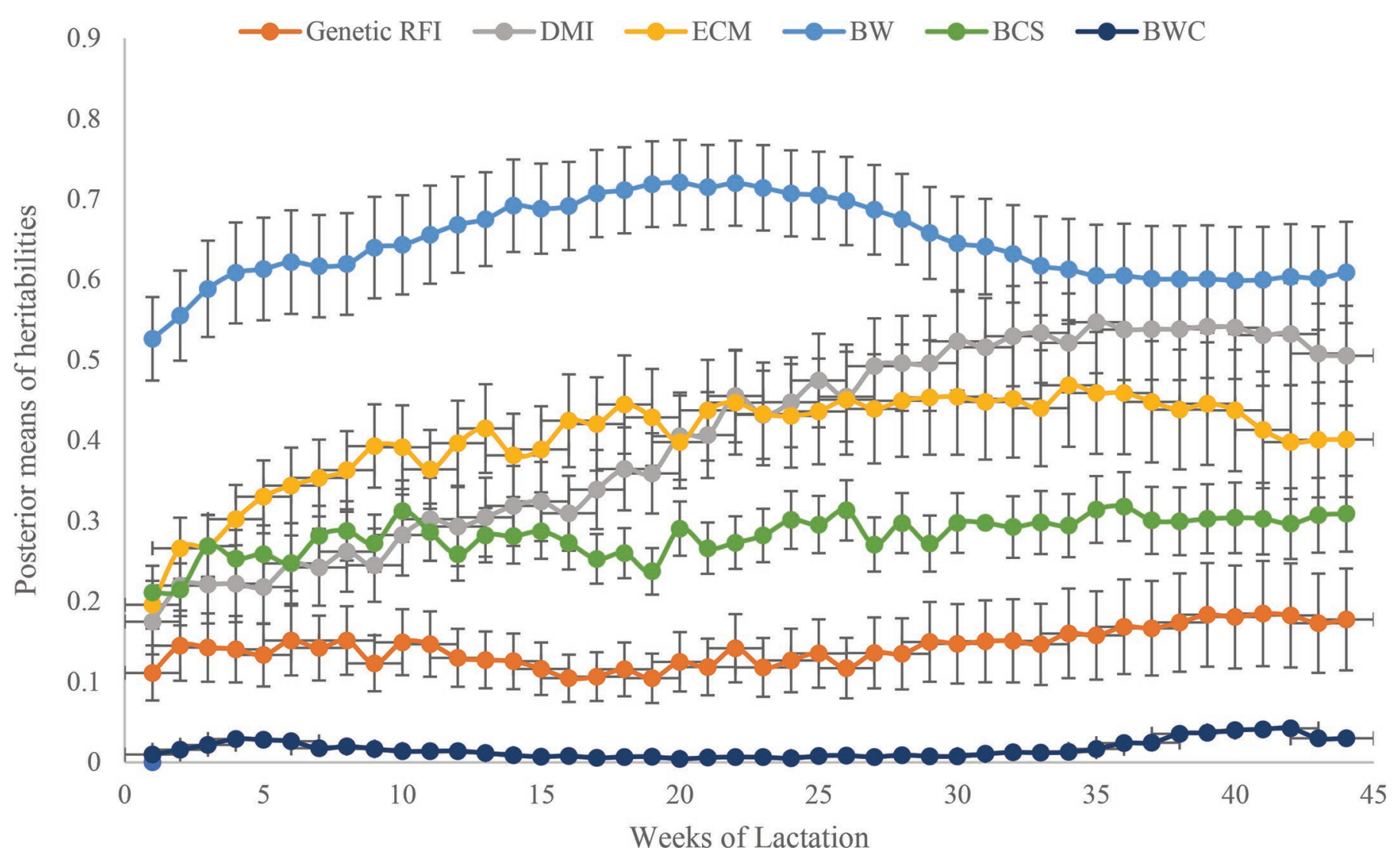

Figure 1. Posterior means $( \pm \mathrm{SD})$ of heritabilities of genetic residual feed intake (RFI, $\mathrm{kg} / \mathrm{d}), \mathrm{DMI}(\mathrm{kg} / \mathrm{d}), \mathrm{ECM}(\mathrm{kg} / \mathrm{d}), \mathrm{BW}(\mathrm{kg}), \mathrm{BCS}, \mathrm{and}$ BW change (BWC) of 847 Danish Holstein cows during their first lactation.

tion was found between RFI and DMI across weeks of lactation but the trend was decreasing in the later parts of lactation. Also, a slightly negative genetic correlation was observed between RFI and DMI in the later part of lactation. Posterior means of available genetic variance for FCR and FCE and the genetic correlations of ratio traits with other traits are shown in Table 2. Because FCR and FCE are ratio traits, the genetic variance for these traits cannot be computed from other variance components without resorting to approximations due to unknown distributional properties of the ratio traits. Here, we applied a Bayesian procedure to estimate genetic variances of ratio traits that accounts for non-normal distributional properties of ratio traits. As expected, FCR and FCE were almost completely negatively genetically correlated due to the definitions of the traits. The posterior means of genetic correlation were moderate and positive between FCR and RFI but moderate and negative between FCE and RFI. Moderate to high posterior means of genetic correlations were found between ratio traits and ECM, and weak correlations were found between ratio traits and DMI. Because we found genetic correlations between FCR and FCE close to -1 , we observed same values of genetic correlations but in the opposite direction between FCR and production traits and FCE and production traits (results not shown).

\section{Effect of DMI on Energy Sinks in Different Weeks of Lactation}

Posterior means of partial genetic and phenotypic regression coefficients of DMI on energy sinks in different weeks of lactation are shown in Figure 7 and Figure 8 , respectively. We found an upward trend of partial phenotypic and genetic regression coefficients of DMI on ECM across different weeks of lactation, indicating that more DMI is needed to produce $1 \mathrm{~kg}$ of ECM as cows move toward late lactation and late pregnancy. Regression coefficients for BW and ECM cannot be compared because these 2 traits have different scale.

\section{Genetic Superiority of the Selected Group}

The posterior means of the direct and correlated superiority of the selected groups for different feed ef- 
ficiency traits are shown in Tables 3,4 , and 5. Direct selection on RFI resulted in a reduction in DMI with no significant change in production traits, although we observed changes in BWC; correlated responses on DMI varied across weeks of lactation. The expected selection response for both FCR and RFI should be negative because the objective is to reduce the feed intake proportion that does not affect maintenance and production. In contrast, the expected selection response for FCE should be positive because the objective is to increase milk yield per unit of DMI. Direct selection for FCR and FCE had a small effect on genetic RFI but we found a significant reduction in BW and BCS due to direct selection on ratio traits. We did not show the results of the response to selection for $\mathrm{FCE}$ because they were similar to those found for FCR but in the opposite direction.

\section{DISCUSSION}

\section{Derivation of RFI}

In this study, we used a Bayesian approach to derive genetic RFI obtained by conditioning breeding values of DMI on breeding values of production traits (ECM, $\mathrm{BW}, \mathrm{BCS}$, and BWC) using partial genetic regression coefficients. We did not compute BWC as a separate trait; instead, we derived it from the random regression model using first differences. This Bayesian approach considers the uncertainty of all unknown parameters in the model. In addition, this approach did not require separate multiple regression analyses to derive RFI. In the current study, we used a multivariate random regression animal model to analyze the data across the different weeks of lactation. Tempelman et al. (2015) derived a 2-stage model for genetic analysis of RFI. In the first stage, linear regression analysis was done to define RFI; then, in the second stage, genetic analysis was done for RFI using pedigree (Tempelman et al., 2015). All the parameters in our one-step model were considered jointly and a 2-step model may not lead to optimal estimates. The one-step model was also derived for RFI in some studies by combining an energy sink model and genetic model (Tempelman et al., 2015; Li et al., 2017). Connor et al. (2013) derived RFI after subtracting predicted energy intake from actual energy intake, where predicted energy intake was obtained from regression analysis. Because we used a multivariate random regression model, we easily obtained BWC in each lactation week from the first derivative of the fitted BW curve of each animal (Li et al., 2017). However, BWC between successive weeks in the current method may increase inevitable errors associated with each weekly observation. Additionally, a random regression animal model is useful to genetically change the lactation profile (Hurley et al., 2017). The model derived in this study did not include all the potential energy sinks such as growth in pregnancy (foster growth), activity, and response to ambient temperature, among others. Furthermore, we had the feed intake record as overall

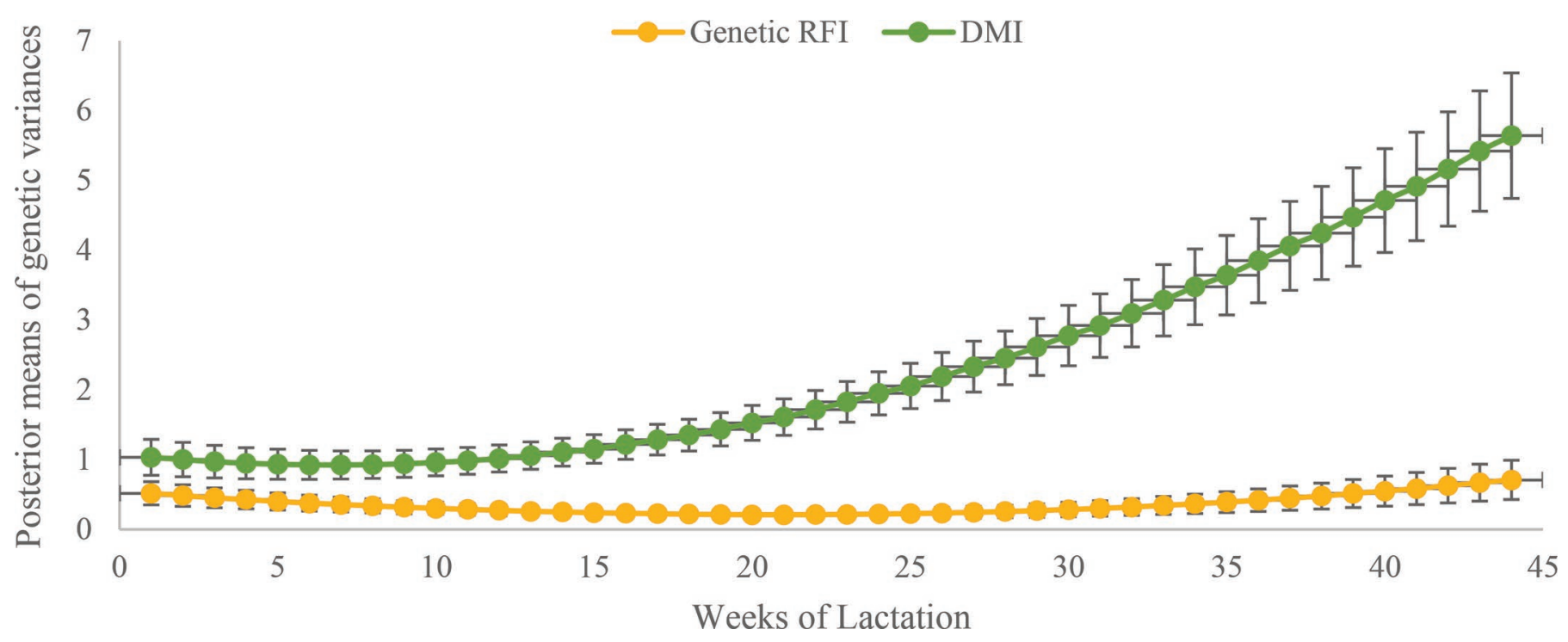

Figure 2. Posterior means $( \pm \mathrm{SD})$ of genetic variances of genetic residual feed intake (RFI, $\mathrm{kg} / \mathrm{d})$ and DMI (kg/d) across 44 wk of the first lactation of 847 Danish Holstein cows. 


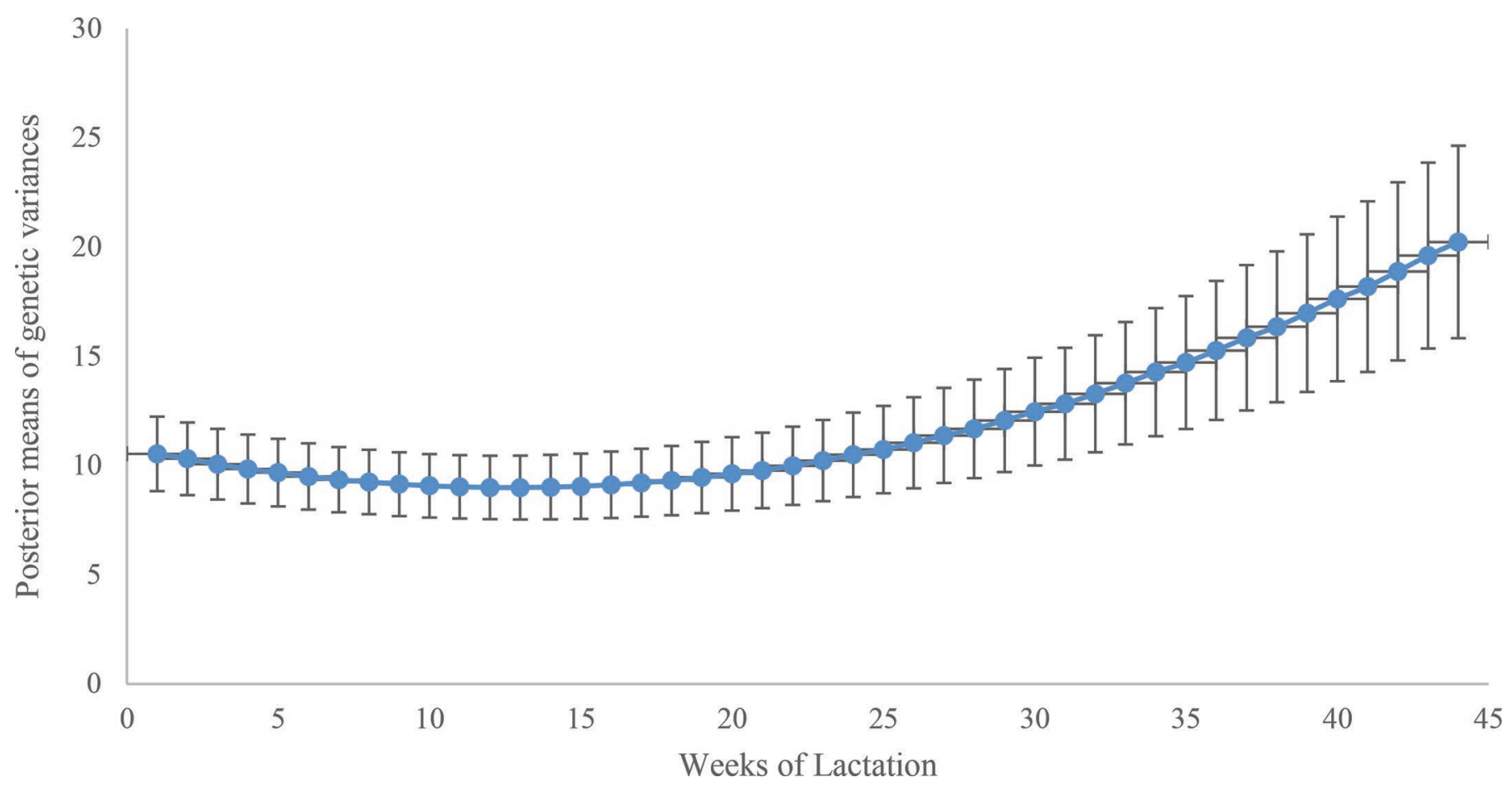

Figure 3. Posterior means $( \pm \mathrm{SD})$ of genetic variances of ECM $(\mathrm{kg} / \mathrm{d})$ across 44 wk of the first lactation of 847 Danish Holstein cows.

DMI. Therefore, we did not investigate the specific feed composition, and as we had a very small data set for feed efficiency analysis, we could not design a season-specific study. However, it will be important to investigate this further using larger data sets. International collation of feed intake data is a potential way to increase the volume of data for feed efficiency analysis. Future research is needed to derive statistical models and include more of the measurable energy sinks to derive genetic RFI.

\section{Derivation of FCR and FCE}

In this study, FCR was derived as the ratio of input (DMI) to output (ECM) using a Bayesian approach, and FCE was estimated as the inverse of FCR. Coleman et al. (2010) defined FCE as a ratio of total DMI to kilograms of BW. Commonly, FCE has been analyzed as a ratio trait of feed efficiency in lactating cows such as milk production per unit intake or milk production per kilogram of BW (Berry and Crowley, 2013). However, these definitions do not consider the fixed and environmental effects affecting the component traits. Shirali et al. (2018) derived a Bayesian approach accounting for the uncertainties of the fixed effects and handling the non-normal distributional properties of the ratio trait. This Bayesian approach was followed to define FCR and FCE in the current study.

\section{Genetic Background of RFI}

Considerable amounts of genetic variance in genetic RFI were found in this study, which suggests that genetic RFI can be used in dairy cattle breeding to improve feed efficiency. Relatively low posterior means of heritability were found for genetic RFI compared with values of heritability for phenotypic RFI found in different studies (Tempelman et al., 2015; Li et al., 2017). We found 10 to $15 \%$ posterior means of heritability for RFI, which is similar to values reported by $\mathrm{Lu}$ et al. (2018) for the heritability of RFI (16\%). $\mathrm{Lu}$ et al. (2018) also defined RFI using partial genotypic regression coefficients that made RFI genetically independent of production traits. Li et al. (2017) estimated heritability for phenotypic RFI ranging from 0.10 to 0.29 , considering partial phenotypic regression coefficients across the periods of lactation. However, when they considered period-specific partial regression coefficients, heritability was found ranging from 0.10 to 0.23 . Tempelman et al. (2015) found around $10 \%$ heritability for phenotypic RFI using 2-step model in US Holstein cows, which agrees with the results of the present study. In contrast, Tempelman et al. (2015) found higher heritability ranging from 15 to $25 \%$ in Dutch Holstein cows. Vallimont et al. (2011) found a low heritability (0.01) for phenotypic RFI, which is much lower than the current study. 


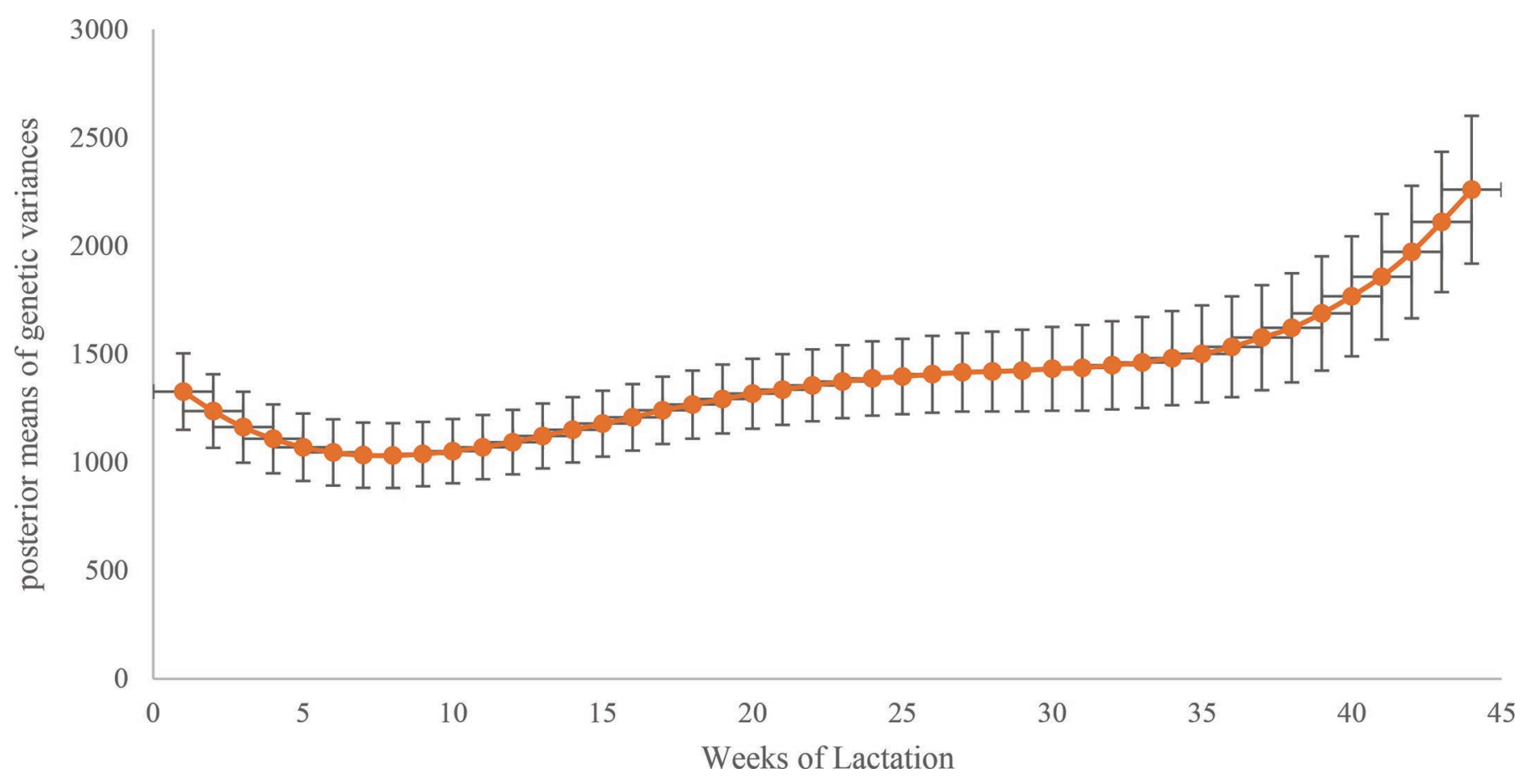

Figure 4. Posterior means $( \pm \mathrm{SD})$ of genetic variances of BW $(\mathrm{kg})$ across 44 wk of the first lactation of 847 Danish Holstein cows.

Heritability of genetic RFI depends on the genetic parameters of feed intake and production traits. The heritability of genetic RFI is expected to be lower than the heritability of phenotypic RFI, although with some exceptions. This is because the genetic variance of genetic RFI is not affected by the residual covariance between production and feed intake, and because the residual covariance between feed intake and the production traits affects the phenotypic RFI, finally resulting in higher heritability of phenotypic RFI than genetic RFI (Kennedy et al., 1993). We observed considerably higher genetic variance for DMI than for genetic RFI. Most of the genetic variance in DMI is determined by the production traits, yet considerable genetic variance in DMI is explained by genetic RFI. For example, 15 to $40 \%$ of genetic variation in DMI was determined by genetic RFI in different weeks of lactation in our study. Shirali et al. (2018) found that genetic RFI explained $26 \%$ of genetic variance in feed intake in pigs.

\section{Genetic Background of DMI and Production Traits}

Posterior means of heritability for DMI was found to be lower in early periods of lactation than previously reported by Li et al. (2016) for Holstein cows from Denmark and Sweden. However, the heritabilities found in mid and late lactation for DMI were in the upper range of values (0.32 to 0.49) reported by Byskov et al. (2017) and Manzanilla Pech et al. (2014) for Holstein cows. Posterior means of genetic variance for DMI showed increasing trend across weeks of lactation, which agrees with the results found by Li et al. (2018). During early lactation, posterior means of heritability for ECM were found to be higher in this study than the value found by $\mathrm{Li}$ et al. (2018), but with a similar stable pattern over the trajectory. In contrast, Manzanilla Pech et al. (2014) found the opposite pattern for heritability such that values increased from low to high from early to late lactation in Dutch Holstein cows. The posterior means of heritability for BW were lower than the values found by Manzanilla Pech et al. (2014) but were in the upper range of values (0.49 to 0.63 ) reported by $\mathrm{Li}$ et al. (2018). Posterior means of heritability for BCS across different periods of lactation in the current study showed a pattern similar to that found by Berry et al. (2003).

\section{Genetic Correlation Between Feed Efficiency and Production Traits}

In this study, we found zero correlation estimates between genetic RFI and production traits, as expected because of the RFI definition used. Following the study of Kennedy et al. (1993), partial genetic regression coefficients were used to derive genetic RFI, and partial genetic regression coefficients must be obtained from 


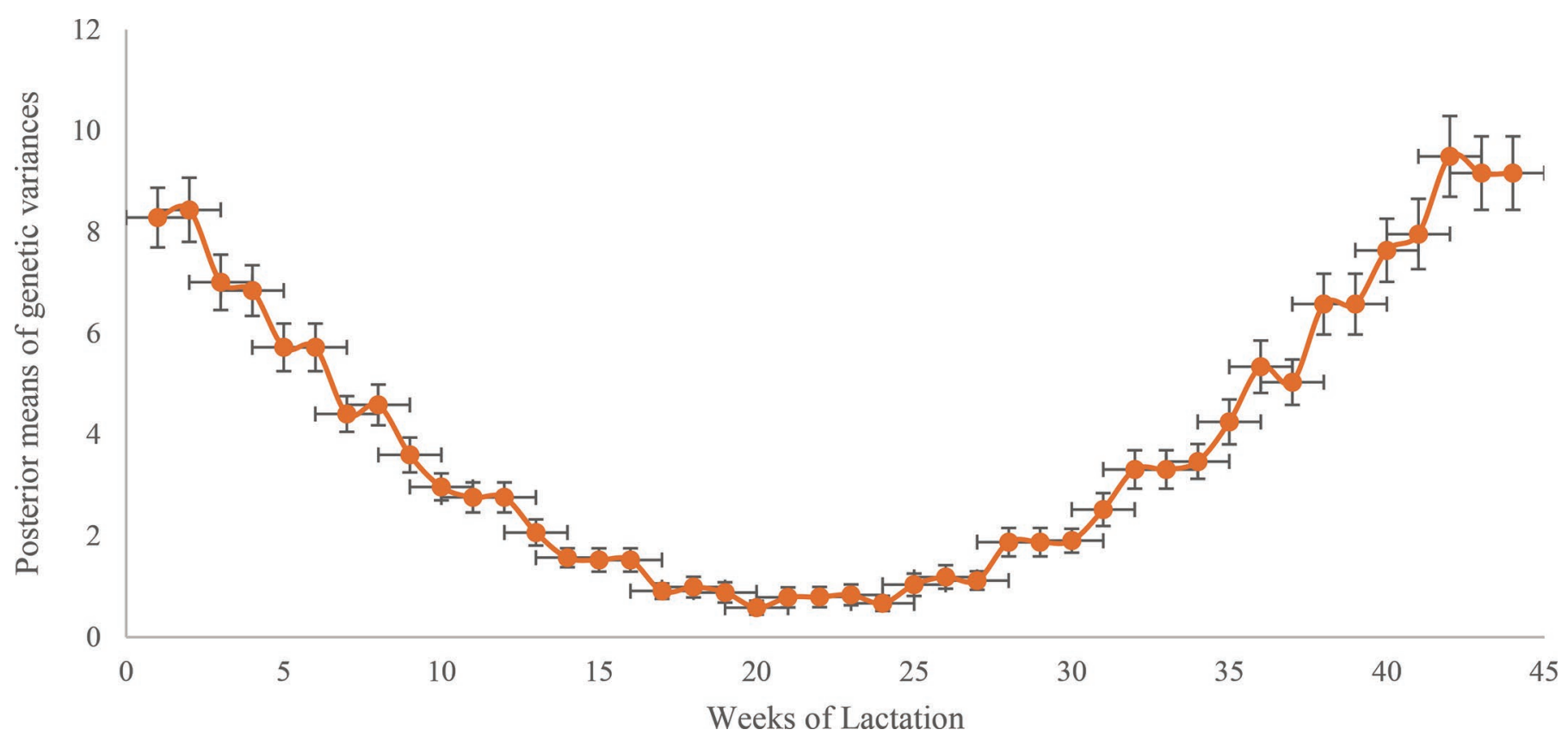

Figure 5. Posterior means of genetic variances of BW change (BWC) across 44 wk of the first lactation of 847 Danish Holstein cows.

genetic variance and covariance components so that genetic RFI is independent of the production traits. However, there would be some phenotypic covariance between genetic RFI and production traits due to environmental covariance, as explained by Kennedy et al. (1993).

We also derived a Bayesian estimate of the genetic variance for the ratio traits (i.e., FCR and FCE), as genetic parameters of ratio traits cannot be estimated directly because of the non-normal distributional properties (Shirali et al., 2018). We found comparatively higher genetic variance for FCE than for FCR. Vallimont et al. (2011) reported that the genetic variance of feed efficiency (defined as 305-d FCM over 305-d DMI) was 0.006 , which is lower than the value of FCE (0.049) and higher than the value of FCR (0.005) observed in our study. We observed moderate to high posterior means of genetic correlations between the ratio traits and the production traits, which agrees with the results reported by Vallimont et al. (2011). Feed conversion ratio and FCE were genetically correlated with production traits, as expected because of the property of the ratio traits (Berry, 2009). It might be expected that the genetic correlation between DMI and FCE would be negative because DMI is the denominator in the ratio, but we found a positive genetic correlation between DMI and FCE, which could be because of the high genetic correlation between DMI (denominator) and ECM (numerator) for FCE. This high genetic correlation might neutralize the negative genetic correlation between FCE and DMI in this study and generate a positive genetic correlation (Vallimont et al., 2011). The correlation of FCR with BW and BCS varied between early and later periods of lactation in this study, perhaps because FCR is the ratio of 2 performance traits having different variance components and means across the lactation trajectory (Hurley et al., 2017). Generally, it is difficult to derive an appropriate measure of feed efficiency in lactating animals with the ratio trait because lactating cows lose body reserve by rapid catabolism in early lactation and then gain weight by anabolism to replenish the body reserves in later lactation. These physiological changes must be accounted for in the definition of feed efficiency but are not accounted for in ratio traits (Berry and Crowley, 2013).

\section{Bayesian Estimation of Genetic Superiority of the Selected Group}

In our study, we derived the genetic superiority of the selected group using a Bayesian approach to investigate effects of using different feed efficiency traits, either linear (genetic RFI) or ratio (FCR and FCE) traits, in dairy cattle breeding. Sorensen et al. (1994) explained that the Bayesian approach provides the marginal posterior distribution of a measure of response to selection that can be described as a weighted average of an infinite number of conditional distributions. The Bayesian approach can also take care of uncertainty in the unknown parameters in the model. Sorensen et al. 
Table 2. Posterior means of available genetic variance for feed conversion ratio $(\mathrm{FCR}, \mathrm{kg} / \mathrm{kg})$ and genetic correlations of FCR with genetic residual feed intake (RFI, $\mathrm{kg} / \mathrm{d})$, feed conversion efficiency (FCE), DMI ( $\mathrm{kg} / \mathrm{d}), \mathrm{ECM}(\mathrm{kg} / \mathrm{d}), \mathrm{BW}(\mathrm{kg}), \mathrm{BCS}$, and change in BW (BWC, $\mathrm{kg}$ ) across weeks of first lactation of 847 Danish Holstein cows (by row)

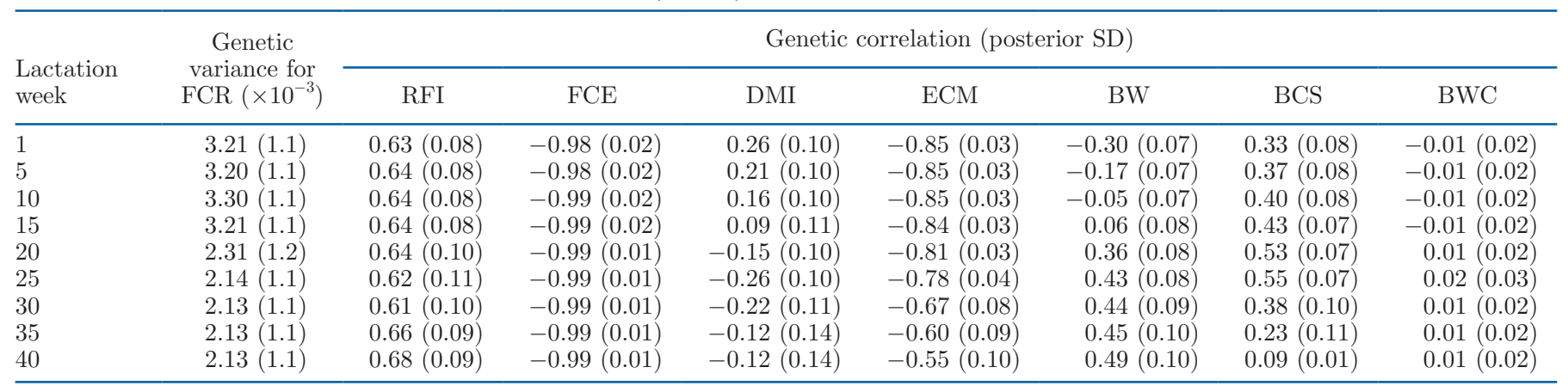

(1994) estimated response to selection in selection experiments over several generations. Here, we estimated the superiority of the selected group within a single generation by conditioning on the genetic trend.

We defined genetic RFI in a way that ensures genetic independence of the production traits, following Kennedy et al. (1993). We then investigated the direct and correlated response to selection for genetic RFI. It is expected that selection for genetic RFI is free of correlated response in production traits and our results confirmed that expectation. Correlated response in feed intake due to selection on genetic RFI was very similar to the direct response to selection on genetic RFI. This agrees with Kennedy et al. (1993), who showed that direct response in genetic RFI is equal to the correlated response in feed intake when selection is performed based on genetic RFI. Moreover, response to selection on genetic RFI depends on the heritability of feed intake, but it also depends on the environmental correlation between feed intake and production traits. Response to selection on genetic RFI increases when heritability of feed intake increases and when the environmental correlation between feed intake and production traits increases. In contrast, response to selection on genetic RFI decreases when heritability of production traits increases and genetic correlation between feed intake and production traits increases. In our study, we found lower heritability of DMI than of BW and ECM only in first period of lactation.

Zetouni et al. (2017) compared selection on a linear multi-trait index or a ratio trait $\left(\mathrm{CH}_{4} / \mathrm{kg}\right.$ of milk) in a dairy cattle population in a simulation study. They found that the multi-trait index was a better way to improve the ratio's component traits than selecting directly for the ratio trait. That confirmed the earlier findings of Gunsett (1984), who showed that there is

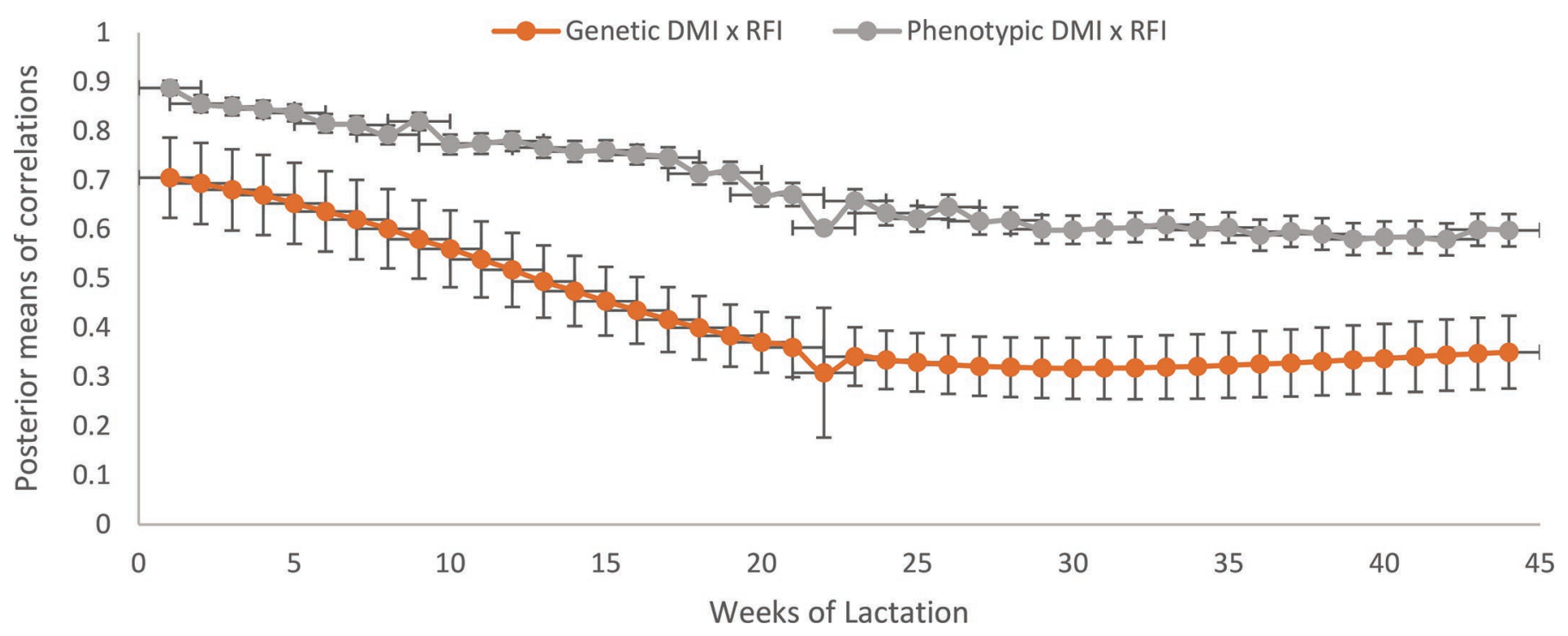

Figure 6. Posterior means $( \pm \mathrm{SD})$ of phenotypic and genetic correlations between DMI $(\mathrm{kg} / \mathrm{d})$ and genetic residual feed intake $(\mathrm{RFI}, \mathrm{kg} / \mathrm{d})$ across $44 \mathrm{wk}$ of the first lactation of 847 Danish Holstein cows. 


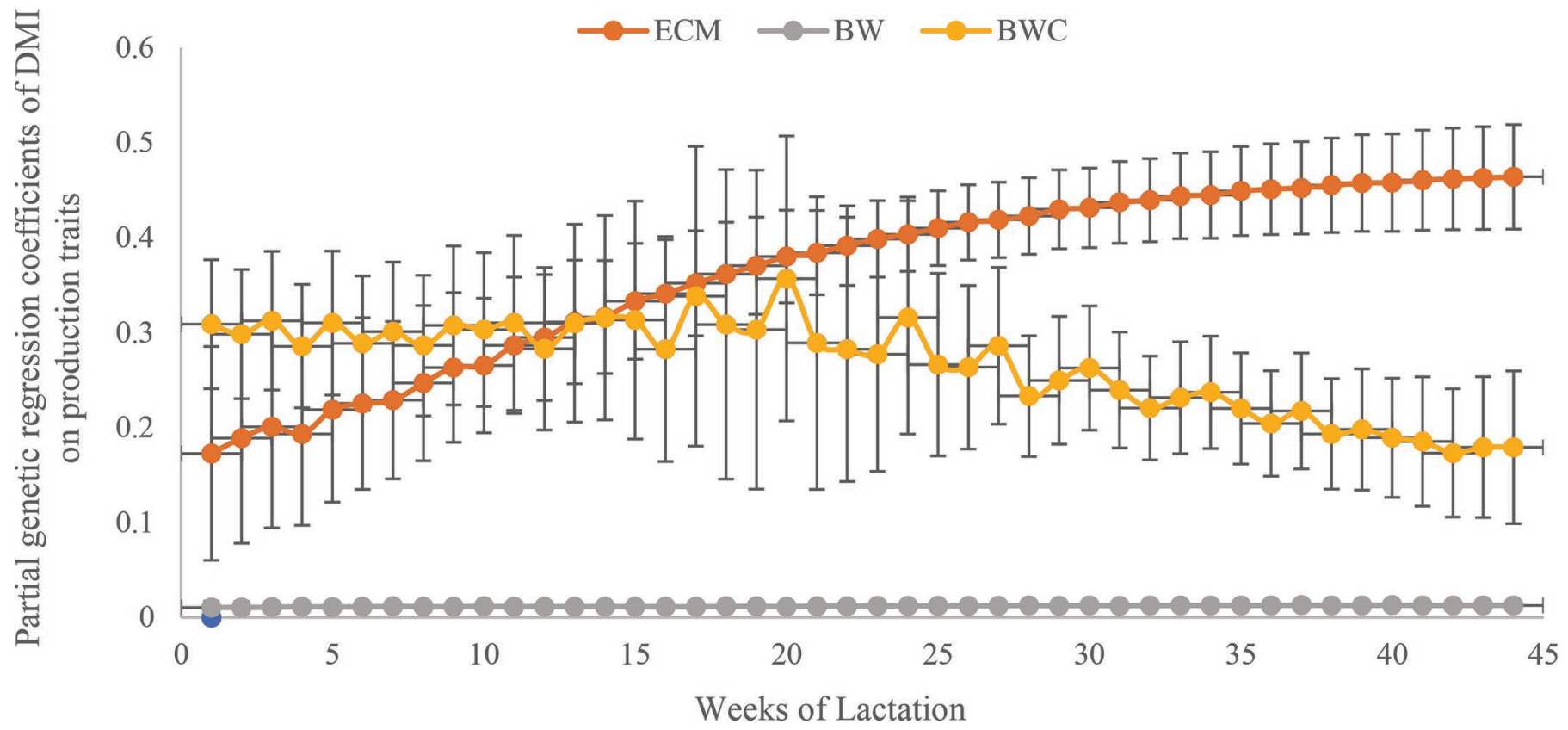

Figure 7. Partial genetic regression coefficients $( \pm \mathrm{SD})$ of DMI $(\mathrm{kg} / \mathrm{d})$ on ECM $(\mathrm{kg} / \mathrm{d}), \mathrm{BW}(\mathrm{kg})$ and BW change (BWC) of 847 Danish Holstein cows in their first lactation.

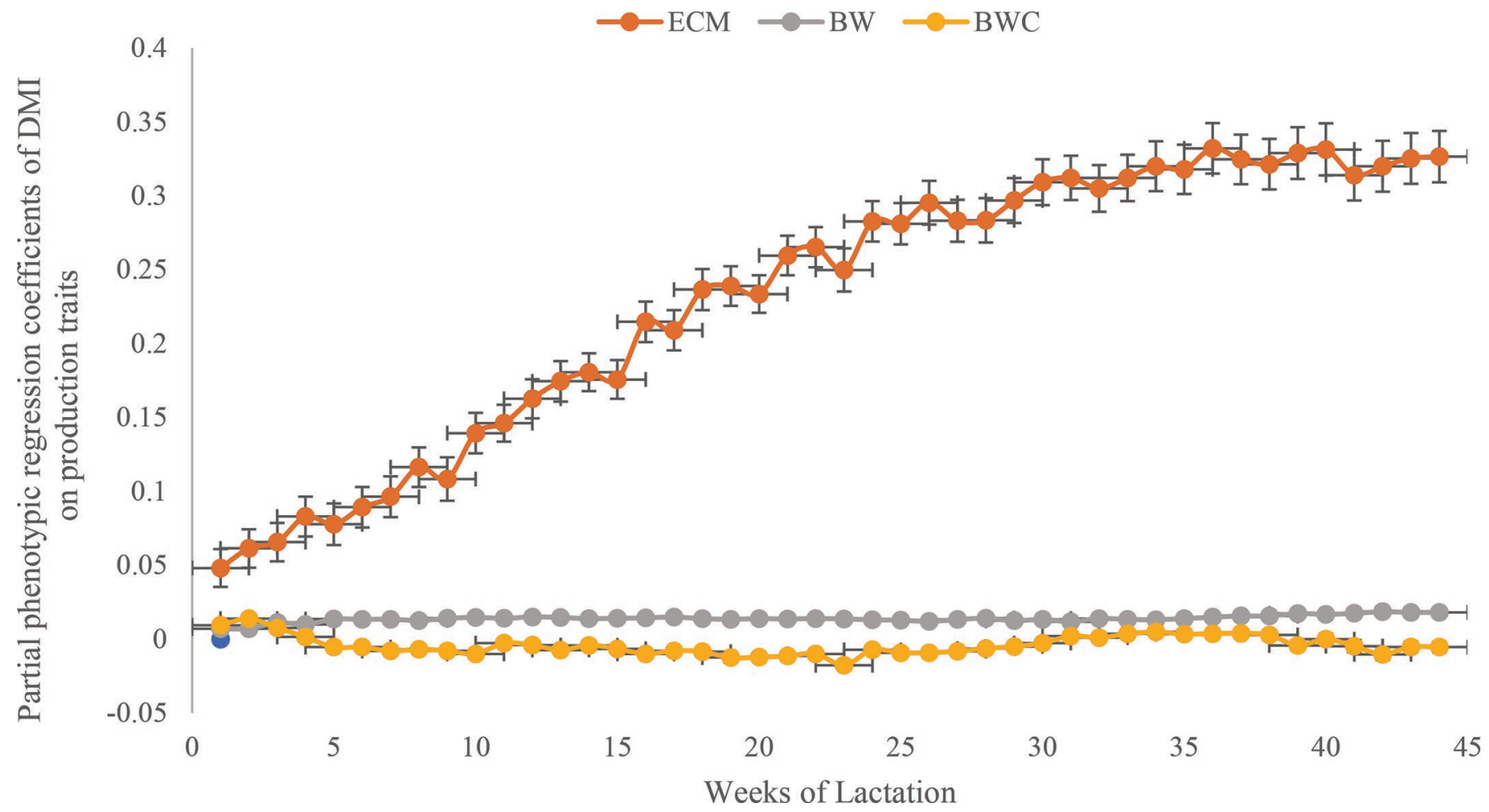

Figure 8. Partial phenotypic regression coefficients $( \pm \mathrm{SD})$ of DMI $(\mathrm{kg} / \mathrm{d})$ on ECM $(\mathrm{kg} / \mathrm{d}), \mathrm{BW}(\mathrm{kg})$, and BW change (BWC) of 847 Danish Holstein cows in their first lactation.

Journal of Dairy Science Vol. 103 No. 10, 2020 
uncertainty about how selection pressure will be distributed on the component traits, depending on the heritability of the traits. As a result, it is difficult to improve the component traits of FCR and FCE by directly selecting on FCR or FCE in dairy cattle. In addition, we found low genetic correlations of DMI with both FCE and FCR. That suggests that reduction of DMI would not be possible by selecting directly on ratio traits. In FCR, the objective is to reduce DMI (numerator) in relation to ECM, whereas, in FCE, the objective is to increase ECM (numerator) in relation to DMI; we found that FCR and FCE are strongly genetically correlated. Accordingly, we observed very similar responses to selection for either FCR or FCE. Gunsett (1984) studied linear index selection to improve traits defined as ratios. The author reported that response to selection is a function of selection intensity of the component traits when selection is done directly on the ratio trait, resulting in problems in predicting genetic gain. Furthermore, response to selection depends on the heritability of the component traits. Direct selection on a ratio trait would be less effective if the heritability of the numerator were less than the heritability of the denominator (Gunsett, 1984).

Lactating dairy cows undergo extensive physiological changes throughout lactation such as catabolism immediately after calving and anabolism of body tissue in the later part of the pregnancy (Roche et al., 2009). Therefore, any measure of feed efficiency in lactating dairy cattle must consider the physiological changes during the lactation period (Berry and Crowley, 2013). There is considerable interest in including feed efficiency traits in the breeding goal. However, there is no consensus about the most appropriate definition of feed efficiency (Berry, 2009). Although FCR is widely used in swine and poultry and is easy to calculate, FCR cannot account for body tissue mobilization in lactating cows. Feed conversion ratio is correlated with component traits and depends on the joint distribution of 2 variables, which results in difficulties in predicting response to selection. The disadvantages of FCR can be overcome with the linear trait RFI, because genetic RFI is genetically independent of the production traits included in the statistical model. Therefore, selection for genetic RFI could produce superior genetics in terms of feed efficiency without affecting production traits. Furthermore, selection for genetic RFI could be useful for studying the biological basis of feed efficiency and feed intake independent of production traits. However, direct and correlated responses to selection on RFI

\section{Selection for RFI Versus Ratio Traits of Feed Efficiency in Lactating Dairy Cattle}

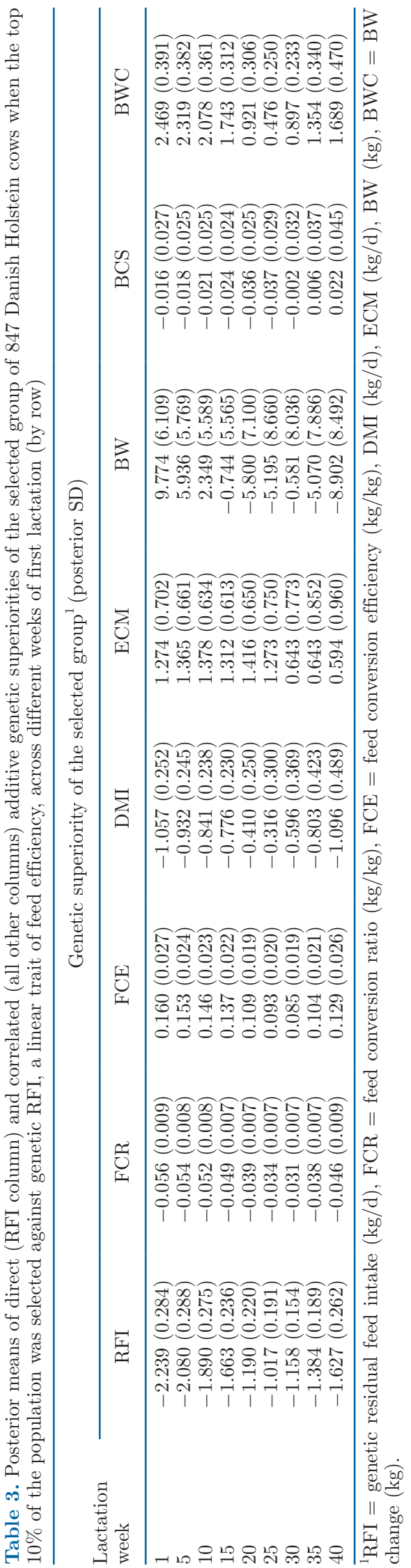

Journal of Dairy Science Vol. 103 No. 10, 2020 

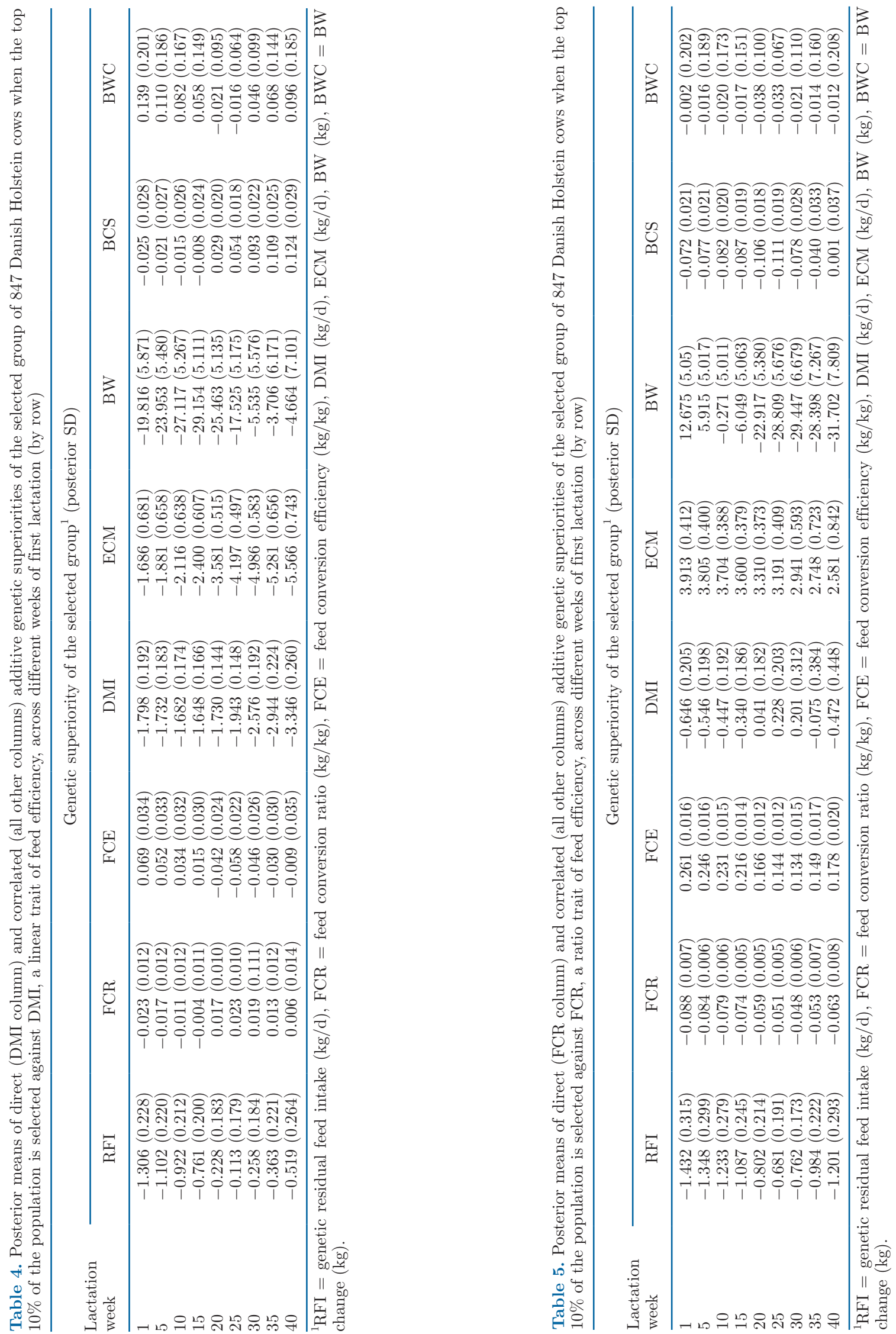
depend on the knowledge of genetic and phenotypic parameters of the component traits (Kennedy et al., 1993).

\section{CONCLUSIONS}

We estimated genetic variance for feed efficiency traits and response to selection for linear or ratio efficiency traits in dairy cattle using a Bayesian procedure. We defined feed efficiency as a linear trait (RFI) using partial genetic regression coefficients so that RFI became genetically independent of the production traits. We also derived the breeding values of FCR and FCE with the Bayesian method, without resorting to approximations. We found weak genetic correlations between ratio traits and DMI, indicating that direct selection for ratio traits would not be effective for reducing feed intake in dairy cattle without affecting body condition. We found that direct selection for genetic RFI did not result in significant change in production traits. Direct selection for ratio traits resulted in the reduction of BW and body condition. Reduction of body condition could have a negative effect on animal health. In comparing genetic RFI and DMI, we can easily communicate with farmers to reduce RFI instead of DMI because DMI is highly genetically correlated with production traits.

\section{ACKNOWLEDGMENTS}

This research was done using data from Danish Cattle Research Center (DCRC, Foulum). This study was supported financially by REMRUM (Innovation fund Denmark, Copenhagen, Denmark), "Feed Utilization in Nordic Cattle," (Milk Levy Foundation, Skejby, Denmark), and "REFFICO" (Green Development and Demonstration Program, GUDP, Denmark) grants. We thank anonymous reviewers for insightful comments on early versions of the manuscript, which led to considerable improvements of the paper. The authors have not stated any conflicts of interest.

\section{REFERENCES}

Berry, D. P. 2009. Improving feed efficiency in cattle with residual feed intake. Pages 67-99 in Recent Advances in Animal Nutrition 2008. P. C. Garnsworthy and J. Wiseman, eds. Nottingham Univ. Press, Nottingham, UK.

Berry, D. P., F. Buckley, P. Dillon, R. D. Evans, M. Rath, and R. F. Veerkamp. 2003. Genetic relationships among body condition score, body weight, milk yield, and fertility in dairy cows. J. Dairy Sci. 86:2193-2204. https://doi.org/10.3168/jds.S0022 -0302(03) 73809-0.

Berry, D. P., M. P. Coffey, J. E. Pryce, Y. de Haas, P. Løvendahl, N. Krattenmacher, J. J. Crowley, Z. Wang, D. Spurlock, K. Weigel, K. Macdonald, and R. F. Veerkamp. 2014. International genetic evaluations for feed intake in dairy cattle through the collation of data from multiple sources. J. Dairy Sci. 97:3894-3905. https://doi .org $/ 10.3168 /$ jds. $2013-7548$.

Berry, D. P., and J. J. Crowley. 2013. Cell Biology Symposium: Genetics of feed efficiency in dairy and beef cattle. J. Anim. Sci. 91:1594-1613. https://doi.org/10.2527/jas.2012-5862.

Byskov, M. V., A. Fogh, and P. Løvendahl. 2017. Genetic parameters of rumination time and feed efficiency traits in primiparous Holstein cows under research and commercial conditions. J. Dairy Sci. 100:9635-9642. https://doi.org/10.3168/jds.2016-12511.

Coleman, J., D. P. Berry, K. M. Pierce, A. Brennan, and B. Horan. 2010. Dry matter intake and feed efficiency profiles of 3 genotypes of Holstein-Friesian within pasture-based systems of milk production. J. Dairy Sci. 93:4318-4331. https://doi.org/10.3168/jds.2009 -2686 .

Connor, E. E., J. L. Hutchison, H. D. Norman, K. M. Olson, C. P. Van Tassell, J. M. Leith, and R. L. Baldwin. 2013. Use of residual feed intake in Holsteins during early lactation shows potential to improve feed efficiency through genetic selection. J. Anim. Sci. 91:3978-3988. https://doi.org/10.2527/jas.2012-5977.

Emmerson, D. A. 1997. Commercial approaches to genetic selection for growth and feed conversion in domestic poultry. Poult. Sci. 76:1121-1125. https://doi.org/10.1093/ps/76.8.1121.

Gunsett, F. C. 1984. Linear index selection to improve traits defined as ratios. J. Anim. Sci. 59:1185-1193. https://doi.org/10.2527/ jas1984.5951185x

Hardie, L. C., M. J. VandeHaar, R. J. Tempelman, K. A. Weigel, L. E. Armentano, G. R. Wiggans, R. F. Veerkamp, Y. de Haas, M. P. Coffey, E. E. Connor, M. D. Hanigan, C. Staples, Z. Wang, J. C. M. Dekkers, and D. M. Spurlock. 2017. The genetic and biological basis of feed efficiency in mid-lactation Holstein dairy cows. J. Dairy Sci. 100:9061-9075. https://doi.org/10.3168/jds.2017-12604.

Hurley, A. M., N. Lopez-Villalobos, S. McParland, E. Lewis, E. Kennedy, M. O'Donovan, J. L. Burke, and D. P. Berry. 2017. Genetics of alternative definitions of feed efficiency in grazing lactating dairy cows. J. Dairy Sci. 100:5501-5514. https://doi.org/10.3168/ jds.2016-12314.

Kennedy, B. W., J. H. J. Vanderwerf, and T. H. E. Meuwissen. 1993. Genetic and statistical properties of residual feed-intake. J. Anim. Sci. 71:3239-3250. https://doi.org/10.2527/1993.71123239x.

Koch, R. M., L. A. Swiger, D. Chambers, and K. E. Gregory. 1963. Efficiency of feed use in beef cattle. J. Anim. Sci. 22:486-494. https: //doi.org/10.2527/jas1963.222486x.

Li, B., B. Berglund, W. F. Fikse, J. Lassen, M. H. Lidauer, P. Mantysaari, and P. Løvendahl. 2017. Neglect of lactation stage leads to naive assessment of residual feed intake in dairy cattle. J. Dairy Sci. 100:9076-9084. https://doi.org/10.3168/jds.2017-12775.

Li, B., W. F. Fikse, J. Lassen, M. H. Lidauer, P. Løvendahl, P. Mantysaari, and B. Berglund. 2016. Genetic parameters for dry matter intake in primiparous Holstein, Nordic Red, and Jersey cows in the first half of lactation. J. Dairy Sci. 99:7232-7239. https://doi.org/ 10.3168/jds.2015-10669.

Li, B., W. F. Fikse, P. Løvendahl, J. Lassen, M. H. Lidauer, P. Mantysaari, and B. Berglund. 2018. Genetic heterogeneity of feed intake, energy-corrected milk, and body weight across lactation in primiparous Holstein, Nordic Red, and Jersey cows. J. Dairy Sci. 101:10011-10021. https://doi.org/10.3168/jds.2018-14611.

Løvendahl, P., and M. G. G. Chagunda. 2011. Covariance among milking frequency, milk yield, and milk composition from automatically milked cows. J. Dairy Sci. 94:5381-5392. https://doi.org/10 .3168/jds.2010-3589.

Løvendahl, P., G. F. Difford, B. Li, M. G. G. Chagunda, P. Huhtanen, M. H. Lidauer, J. Lassen, and P. Lund. 2018. Review: Selecting for improved feed efficiency and reduced methane emissions in dairy cattle. Animal 12(s2):s336-349. https://doi.org/10.1017/ S1751731118002276.

Lu, Y., M. J. Vandehaar, D. M. Spurlock, K. A. Weigel, L. E. Armentano, E. E. Connor, M. Coffey, R. F. Veerkamp, Y. de Haas, C. R. Staples, Z. Wang, M. D. Hanigan, and R. J. Tempelman. 2018. Genome-wide association analyses based on a multiple trait approach for modeling feed efficiency. J. Dairy Sci. 101:3140-3154. https://doi.org/10.3168/jds.2017-13364. 
Madsen, P., and J. Jensen. 2013. DMU-A Package for Analyzing Multivariate Mixed Models. Version 6, Release 5.2. Quantitative Genetics and Genomics (QGG), Aarhus University, Tjele, Denmark.

Manzanilla Pech, C. I. V., R. F. Veerkamp, M. P. L. Calus, R. Zom, A. van Knegsel, J. E. Pryce, and Y. De Haas. 2014. Genetic parameters across lactation for feed intake, fat-and protein-corrected milk, and liveweight in first-parity Holstein cattle. J. Dairy Sci. 97:5851-5862. https://doi.org/10.3168/jds.2014-8165.

Roche, J. R., N. C. Friggens, J. K. Kay, M. W. Fisher, K. J. Stafford, and D. P. Berry. 2009. Invited review: Body condition score and its association with dairy cow productivity, health, and welfare. J. Dairy Sci. 92:5769-5801. https://doi.org/10.3168/jds.2009-2431.

Shirali, M., P. F. Varley, and J. Jensen. 2018. Bayesian estimation of direct and correlated responses to selection on linear or ratio expressions of feed efficiency in pigs. Genet. Sel. Evol. 50:33. https:/ /doi.org/10.1186/s12711-018-0403-0.

Sjaunja, L. O., L. Baevre, L. Junkkarinen, J. Pedersen, and J. Setala. 1990. A Nordic proposal for an energy corrected milk (ECM) formula. Pages 156-157 in Proc. 27th Biennial Session Int. Cttee. Anim. Recording (ICAR), Paris, France. EAAP Publication No. 50, Center for Agricultural Publishing and Documentation (Pudoc), Wageningen, the Netherlands.

Smith, B. J. 2007. BOA: An R package for MCMC output convergence assessment and posterior inference. J. Stat. Softw. 21:1-37. https: //doi.org/10.18637/jss.v021.i11.

Sorensen, D. A., C. S. Wang, J. Jensen, and D. Gianola. 1994. Bayesian analysis of genetic change due to selection using Gibbs sampling. Genet. Sel. Evol. 26:333-360. https://doi.org/10.1186/1297 -9686-26-4-333.
Tempelman, R. J., D. M. Spurlock, M. Coffey, R. F. Veerkamp, L. E. Armentano, K. A. Weigel, Y. de Haas, C. R. Staples, E. E. Connor, Y. Lu, and M. J. VandeHaar. 2015. Heterogeneity in genetic and nongenetic variation and energy sink relationships for residual feed intake across research stations and countries. J. Dairy Sci. 98:2013-2026. https://doi.org/10.3168/jds.2014.8510.

Vallimont, J. E., C. D. Dechow, J. M. Daubert, M. W. Dekleva, J. W. Blum, C. M. Barlieb, W. Liu, G. A. Varga, A. J. Heinrichs, and C. R. Baumrucker. 2011. Short communication: Heritability of gross feed efficiency and associations with yield, intake, residual intake, body weight, and body condition score in 11 commercial Pennsylvania tie stalls. J. Dairy Sci. 94:2108-2113. https://doi.org/10 .3168/jds.2010-3888.

Zetouni, L., M. Henryon, M. Kargo, and J. Lassen. 2017. Direct multitrait selection realizes the highest genetic response for ratio traits. J. Anim. Sci. 95:1921-1925. https://doi.org/10.2527/jas2016.1324.

\section{ORCIDS}

M. S. Islam ๑ https://orcid.org/0000-0003-2442-6869

J. Jensen () https://orcid.org/0000-0003-3291-8468

P. Løvendahl ๑ https://orcid.org/0000-0002-9852-2944

P. Karlskov-Mortensen (i) https://orcid.org/0000-0002-2491-2763

M. Shirali (๑ https://orcid.org/0000-0001-9893-831X 